\title{
An Account of Phonetics and Phonology as Similar Identical or Different
}

\author{
Ahmed M. S. Alduais ${ }^{1 *}$
}

\section{ABSTRACT}

Purpose: Where do phonetics and phonology meet and differ from one another as two field of linguistics? Method: The study is mainly descriptive where previous and related studies are reviewed and presented to reach a view about phonetics and phonology as similar, different or identical. Results: Phonetics and phonology are two different fields of linguistics which are related to one another. Phonetics is the concrete study of sounds. On the other hand, phonology is the abstract study of sounds. Moreover, phonetics and phonology are integrated two fields of linguistics but they are not identical. Conclusions: Phonetics is concrete in contrast to phonology which is abstract. Additionally, phonetics is learned while phonology is acquired.

Keywords: Phonetics, Phonology

It is a well-known fact that two persons, things cannot be identical. That is to say, what you will imagine if you and your brother are exactly the same? It is true that you might be physically the same but mentally, are not. More clearly, the Sun and the Moon are both two planets; each one gives us light; each one serves all creatures including human beings. But, not each one of them produces heat. Yet, and more importantly, light produced by the sun is greatly different from light produced by the moon. The point is, two sciences, minds, creatures cannot be exactly the same! In other words, they can share some features, components and yet differ from one another in some other features. So, Phonetics and Phonology's issue is exactly like the issue of the sun and the moon. Put another way, if both are the same, so no need for one of them. However, it is worthwhile to discuss such an issue and attempt to decide the reality behind these two linguistics fields.

As a matter of fact and as long as these two terms have been discussed and studied by many researchers and linguists; the researcher; however, will attempt a briefly discussion of what has been introduced and presented by those researchers. Hence, the researcher is going to present the topic from the point of view of two main points: similarities and differences between Phonetics and Phonology.

\footnotetext{
${ }^{1}$ Department of Linguistics, Social Sciences Institute, Ankara University, 06100, Sihhiye, Ankara, Turkey *Corresponding Author (C) 2015 I A Alduais; licensee IJIP. This is an Open Access Research distributed under the terms of the Creative Commons Attribution License (http://creativecommons.org/licenses/by/2.0), which permits unrestricted use, distribution, and reproduction in any Medium, provided the original work is properly cited.
} 


\section{An Account of Phonetics and Phonology as Similar Identical or Different}

Naturally speaking and with reference to the written and presented papers regarding this topic one can find that even those researchers and linguists have not yet made a clear-cut points between phonetics and phonology. In spite of this, some from among those linguists and researcher have done their best in order to set the exactly differences between phonetics and phonology and at the same time their definitions. Thus, some of these discussions, particularly, the most recent ones, will be presented briefly in a way that investigates the differences and similarities between phonetics and phonology.

So, let us put a question which can help us discuss this topic and decide whether such two fields are similar, different, or identical? The question is, to what extent the following statement can be true” phonetics and phonology are different but alike”.

\section{Phonetics and Phonology: Definitions}

Primarily, it is thought by the researcher that mentioning some of the definitions of these two fields will partly help to decide the similarities and differences between them. On his book; however, Roach (1992:81) defines phonetics as:

The scientific study of speech... the central concern in phonetics are the discovery of how speech sounds are produced, how they are used in spoken language, how we can record speech sounds with written symbols, and how we hear and recognize different sounds.

Phonology, on the other hand, he states(ibid:82) "the study of the sound systems of languages. The most basic activity in phonology is phonemic analysis, in which the objective is to establish what the phonemes are and arrive at the phonemic inventory of the language”.

Another definition for each one is given by Widdowson (1996:42). He claims that the study of the allophonic manifestation, how the sounds of speech are actually made, is the business of phonetics." He continues (1996: 42) "the study of phonemes and their relations in sound systems is the business of phonology".

One more definition is introduced by Kelly (2000:9). He declares:

The study of pronunciation consists of two fields, namely phonetics and phonology. Phonetics refers to the study of sounds. A phonetician usually works in one or more of the following areas: physiological phonetics, articulatory phonetics, acoustic phonetics, auditory phonetics and perceptual phonetics.

He goes on defining phonology along with phonetics(2000:9) "if phonetics deals with the physical reality of speech sounds then phonology, on the other hand, is concerned with how we 
interpret and systematize sounds. Phonology deals with the system and pattern of the sounds which exist with particular languages”.

Another definition is stated by Yule (2006:30). He states that "phonetics is the general study of the characteristics of speech sounds" whereas, phonology, (2006: 43-4), “... is essentially the description of the system of patterns of speech sounds in a language. It is, in effect, based on a theory of what every speaker of a language unconsciously knows about the sound patterns of that language.' He continues (ibid)," because of their theoretical status, phonology is concerned with the abstract or mental aspect of the sounds in language rather than with the actual physical articulation of speech sounds."

Yet, Sloat, Taylor \& Hoard (1978:1) introduce phonology as the "the science of speech sounds and sound patterns.” And, they clarify their definition mentioning that (ibid)' a sound pattern we mean: 1) the set of sounds that occur in a given language, 2) the permissible arrangement of these sounds in words, and (3) the processes of adding or changing sounds'. Unlike phonology, they claim that (ibid:9)" the science of phonetics provides descriptions and classifications of speech sounds'. They, however, are trying to set some differences between both phonetics and phonology (ibid: 9) "phonology employs these descriptions and classifications to describe sound systems and explain sound processes”.

Well, if we come to analyse and compare the above mentioned definitions, we can reach to a point or more regarding the similarities and differences between phonetics and phonology. For instance, Roach (1992), Widdowson (1996), Kelly (2000), and nearly all other mentioned definitions share one idea regarding this topic. That is to say, they almost all agree with the idea that both phonetics and phonology "are the study of sounds systems”. But, after introducing this point, each one brings some principles which are either available in phonetics or phonology. To make it clear, in Co-build Advanced Dictionary(2001:1153) defines both phonetics and phonology as" the study of speech sounds" and then adding to distinguish phonology from phonetics (ibid) "phonology is the study of speech sounds in a particular language' .

Unlike Collins’ definition, Kelly (ibid:9) criticizes such an idea which says that phonology is monolingual; "it would be wrong to assume that phonology is always monolingual." It seems that his view is phonology is beyond the idea which says that phonology studies the sounds systems in a particular language. He confirms this by his statement (ibid: 9) "much work in phonological study deals with generalization concerning the organization and interpretation of sounds that might apply across different languages.”

Again, if we look at those definitions carefully; we may come to the result that all those who have defined phonetics concentrate on the word [physical]. That is to say, they are all sharing the same opinion which says that the business of phonetics is to introduce the sounds' production. 
Phonology, on the other hand, is concerned with the mental side; a point which again, all the above mentioned definitions share.

\section{Phonetics and Phonology: Similarities and Differences}

In addition to what has been mentioned above is the following listed points which are introduced by a number of researchers/ linguists/ phoneticians/ phonologists. Each one of them; however, attempts to identify the business of each concept, its principles and yet in what principles or features each one is different from the other.

\section{Table 1: Phonetics and phonology in comparison}

\begin{tabular}{|c|c|}
\hline Phonetics & Phonology \\
\hline $\begin{array}{l}\text { Feller(2007): } \\
\text { - Studies of the sounds themselves } \\
\text { - Looks at the physical knowledge } \\
\text { and present it } \\
\text { - Allows a person to know about the } \\
\text { sound which s/he produces }\end{array}$ & $\begin{array}{l}\text { - Studies the ways in which speech } \\
\text { sounds form systems and patterns } \\
\text { - Looks at mental knowledge and } \\
\text { describe it } \\
\text { - Allows speakers of a language to } \\
\text { produce meaningful sounds or to } \\
\text { recognize a foreign language }\end{array}$ \\
\hline $\begin{array}{l}\text { Anderson: } \\
\text { - Deals with the properties of sounds } \\
\text { from a language independent point } \\
\text { of view } \\
\text { - Concrete }\end{array}$ & $\begin{array}{l}\text { - Constitutes the study of the sound } \\
\text { structure of units (morphemes, } \\
\text { words, phrases, utterances) within } \\
\text { individual languages } \\
\text { - To elucidate the systems of } \\
\text { distinctions in sound which } \\
\text { differentiate such units within a } \\
\text { particular language } \\
\text { - Studies invariant of sounds } \\
\text { structure and of the variation } \\
\text { - Abstract }\end{array}$ \\
\hline Arizona website & $\begin{array}{l}\text { - the study of the patterned } \\
\text { interaction of speech sounds } \\
\text { - describes the rules or conditions on } \\
\text { sounds and sound structures that } \\
\text { are possible in particular languages } \\
\text { - accounts for the similarities among } \\
\text { human languages e.g. (all } \\
\text { consonants inventories have } \\
\text { voiceless stops, all languages have } \\
\text { also syllables universals } \\
\text { defines the space of possible } \\
\text { sounds and sound structures that all } \\
\text { human languages draw from }\end{array}$ \\
\hline
\end{tabular}




\begin{tabular}{|c|c|}
\hline $\begin{array}{l}\text { Lingual links library: } \\
\text { - basis for phonological analysis } \\
\text { - analyzes the production of all } \\
\text { human speech sounds, regardless of } \\
\text { the language }\end{array}$ & $\begin{array}{l}\text { - basis for further work in } \\
\text { morphology, syntax, discourse and } \\
\text { anthropology design } \backslash \\
\text { - analyses the sound patterns of a } \\
\text { particular language by determining } \\
\text { which phonetic sound are } \\
\text { significant, and } \\
\text { - explains how these sounds are } \\
\text { interpreted by the native speaker }\end{array}$ \\
\hline $\begin{array}{l}\text { Columbia encyclopedia: } \\
\text { - the study of the production, } \\
\text { perception, and physical properties } \\
\text { of speech sounds }\end{array}$ & \\
\hline $\begin{array}{l}\text { SormadHussian: } \\
\text { - Studies human speech as physical } \\
\text { phenomenon } \\
\text { - } \text { Discusses areas such as articulation, } \\
\text { acoustics, and perception }\end{array}$ & $\begin{array}{l}\text { - The study of how sounds interact in } \\
\text { various languages and discusses } \\
\text { topics such as: segmental } \\
\text { phenomena, phonemic inventory } \\
\text { and allophones, sound-change } \\
\text { rules of ordering } \\
\text { - Supra-segmental phenomena: } \\
\text { syllabification, prominence, tones, } \\
\text { intonation }\end{array}$ \\
\hline $\begin{array}{l}\text { Cohn: } \\
\text { - Phonetics effects and constraints are } \\
\text { reflected in the phonology under the } \\
\text { theory of ( Naturalness) } \\
\text { - Continues } \\
\text { - Gradient }\end{array}$ & $\begin{array}{l}\text { - Phonology in phonetics: how units } \\
\text { of phonology and their physical } \\
\text { realization, phonological } \\
\text { knowledge is realized in and } \\
\text { extracted from the physical signal, } \\
\text { phonological contrast is physically } \\
\text { realized } \\
\text { - Discrete } \\
\text { - Categorical }\end{array}$ \\
\hline
\end{tabular}

\section{DISCUSSION}

With reference to the above listed points, one can infer that phonetics and phonology are two different sub-fields in linguistics. Put it another way, they both study the pronunciation of the language but the way each one of them studies/introduces the pronunciation is entirely different from one another. It is true that they are both as shown” interested in speech sounds' but the way of interest, again, is different. However, it has been mentioned that "phonetics is the basis for phonological analysis". In contrast to phonetics, phonology is mentioned as" a basis for a further work in morphology, words, syntax...etc". This suggests that phonetics and phonology are interacted or each one is related entirely to the other one. 
As a consequence, one may assume that phonology starts from where in phonetics ends! In other words, since phonetics is introduced as the study of how the sounds are produced, articulated and so on, so it will be the job of phonology to complete what phonetics has started. Such issues are determined as how the sounds are” combined, organized and convey meaning in particular languages”.

For that matter, even the researches, workshop papers, and work papers that have been done till now did not make a clear cut points between phonetics and phonology. Put it differently, such researchers may have determined/ identified a number of principles as similar and some others as dissimilar but still some of those presented/ introduced principles are unclearly introduced/ presented. For example, Schreuder etal. (2004:1-6) introduce their work paper claiming that phonology can stand on its own principles with no need to the basis of phonetics. They tried to prove such an idea through discussing the Schwa-insertion in syllable final-consonant clusters. Furthermore, they also attempt to prove that phonetics and phonology as interacted through discussing the realization of liquids in first language acquisition. They also add to their discussion one more issue which is as they call it(the problematic phonetic analysis) and they discuss it through (phonemically variable patterns).

Consequently, they come out with that the "schwa- insertion” process" can only be described in a phonological way", (ibid). Regarding the second point, they conclude that "obviously, phonology needs the phonetic information to explain this process as an unmarked (widely attested) one. And for the last one the state” apparently not all phonological processes can be tested empirically by phonetic analysis”, (2004:1-6).

Looking carefully at the results of this paper, it suggests that phonetics and phonology are different yet alike. More clearly, they are both sub-linguistic fields which share some principles and differ in some other principles. Yet, each of both can stand on itself.

Dissimilarly, some other researchers may argue against this view such as Cohn. On his work paper (2007:25) he argues in favour of the idea that phonetics is very much related to phonology and on the opposite phonology is very much related to phonetics. He namely calls this(ibid:25) "phonetics in phonology and phonology in phonetics'. He explains these two issues through that phonetics is related to phonology in its naturalness. That is to say, he attempts to prove through a linguistic theory which suggests that the naturalness of phonetics is basically from the naturalness of phonology. His another idea is that” phonology in phonetics' which again he discusses through "the way that phonological contrast and patterns are realized in the physical signal'. Thus, he concludes his paper with that' phonetics and phonology are multifaceted” ones. This point suggests that though the researcher mentions that phonetics and phonology are interacted but at the end he admits that (ibid:26) 
To reach a fuller understanding of the workings of phonology, phonetics, the lexicon, and their interactions, we need be willing to reconsider widely held assumptions and ask in an empirically-based way what is the connection between these domains of the linguistic system. What is called for are non-reductionist integrated approaches. Once we accept the profound complexity of what we are trying to describe and explain, we will discover that many of the contributions of generative linguistics and psycholinguistics often framed as being in opposition are in fact compatible and together offer an explanation of the nature of sounds systems, in terms of their mental representations, production, perception, acquisition, and use.

Similar to Cohn is Odden(2005:2) whose claim is that phonetics is entirely related to phonology and he believes that a good way for understanding phonology can be only with studying it with other subjects. He claimsone way to understand what the subject matter of phonology is, is to contrast it with fields within linguistics”. Yet, Odden starts his book by proposing that(2005:2) 'making a principled separation between phonetics and phonology is difficult- just as it is difficult to make principled separation between physics and chemistry, or sociology and Anthropology". However, he then maintains (ibid) "a better understanding of many issues in phonology requires that you bring phonetics into consideration, just as a phonological analysis is a prerequisite for any phonetic study of language”.

Hence, just like many of the early mentioned researches, Odden(ibid:2) also comes out with that phonology is a mental and abstract process; whereas, phonetics is concrete and physical.

At last, it is worthwhile to mention that may be a large number of the linguistic theories have risen underlining the purpose of setting the principles and the nature of both phonetics and phonology. From amongst these theories are: The Distinctive Feature Theory, Auto segmental Theory, Laboratory Theory, Prosody, Optimality Theory, and recently Articulatory Theory,(2004:1-10).

Lastly but not the least, Parenchyma presents the differences between phonetics in phonology in cartoons as shown below.

Figure 1: Phonetics and phonology in comparison

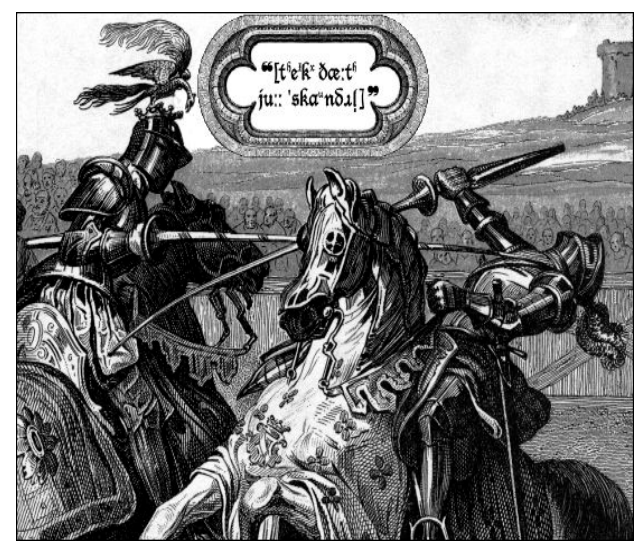

Phonetics

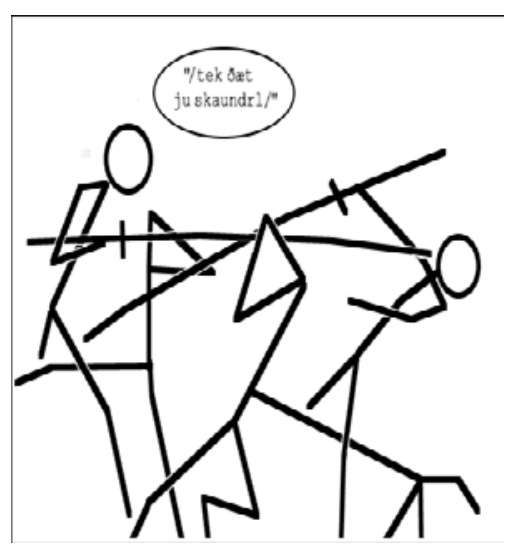

Phonology 


\section{CONCLUSION}

To conclude, the claim of the researcher that phonetics and phonology are different but alike is to great extent true. That is to say, it has been proved through the presented views that phonetics is related to phonology and vice versa. Yet, each one of these two linguistic sub-fields can be studied and presented depending on its own principles and rules. But and more importantly, if we want to introduce/ present any of these two concepts perfectly; here phonetics should come with phonology and phonology comes with phonetics.

\section{REFERENCES}

Anderson, Stephen R. (2001). "Phonology.” in N. J. Smelser and Paul B. Baltes [eds.], International Encyclopedia of the Social and Behavioral Sciences. Oxford: Pergamon. pp. 11386-11392.

Cohn C. A., Phonetics in Phonology and Phonology in Phonetics, Working Papers of the Cornell Phonetics Laboratory, 2007, v.16, pp. 1-31.

Feller R., (2007), Phonetics and Phonology. Available at:

http://www.altavista.com/web/results?itag=ody\&\%20phonology\&kgs=1\&kls=0\&r1=v2\&\%20ph onology\&r1=v2\&q=phonetics $\% 26+$ phonology\&stq $=20$

Hussain S., (n.d.). Phonetics \& Phonology: An Introduction, Center for Research in Urdu Language Processing, NUCES, Lahore, Pakistan. Available at:

http://www.panl10n.net/Presentations/Cambodia/Sarmad/Phonetics\&Phonology.pdf13/12/2008

Kelly G. (2000) How to Teach Pronunciation, Longman: Longman Press.

Ladefoged P., (2004). 50 years of Phonetics and Phonology, From Sound to Sense. MIT Dept. Linguistics, UCLA. Los Angeles, USA. Available at: http://www.rle.mit.edu/soundtosense/conference/pdfs/invitedspeakers/Ladefoged\%20PA PER.pdf

Lingua Links Library. (2004). What is phonology? SIL International. Available at: http://www-01.sil.org/linguistics/glossaryoflinguisticterms/WhatIsPhonology.htm

Muller, K. (2007), Phonetics and its Uses in Foreign Language Instruction. Available at: http://www.teflcorp.com/articles/complete_articles.php?index=448\&category=62 $15 / 12 / 2008$

Odden, D., (2005). Introducing Phonology, Cambridge: Cambridge University press.

Parenchyma, H. (2007). Cartoon Theories of Linguistics: Part E-Phonetics vs. Phonology. SpecGram. Vol CLIII, No 1.

"Phonology." The Columbia Encyclopedia, 6th ed.. 2015. Retrieved September 21, 2015 from Encyclopedia.com: http://www.encyclopedia.com/doc/1E1-phonolog.html

"Phonetics." The Columbia Encyclopedia, 6th ed.. 2015. Retrieved September 21, 2015 from Encyclopedia.com: http://www.encyclopedia.com/doc/1E1-phonetic.html

Purnell, T. (2009). Phonetic Influence on Phonological Operations. In E. Raimy, \& C. E. Cairns, Contemporary Views on Architecture and Representations in Phonology. MIT Press.

Roach P., (1992), Introducing Phonetics, London, London Penguin English Group. 
Sloat C. \& others, (1978), Introduction to Phonology, Prentice-Hall. Inc., Englewood Cliffs: USA.

Schreuder M. \& others, (2004), On the Boundaries of Phonology and Phonetics, Groningen 30 January Workshop. Available at:

http://odur.let.rug.nl/ schreudr/ppt/phoneticsinphonology/handoutboundaries.pdf $15 / 12 / 2008$

The Language Samples Project. (2001), Phonetics. Anthropology Department of the University of Arizona, USA. Available at:

http://ic migration.webhost.uits.arizona.edu/icfiles/ic/lsp/site/index.html

The Language Samples Project. (2001), Phonology. Anthropology Department of the University of Arizona, USA. Available at:

http://ic-migration.webhost.uits.arizona.edu/icfiles/ic/lsp/site/index.html

Widdowson G. H., (1996), Oxford introductions to Linguistics: Linguistics, Oxford: Oxford University Press.

Yule G., (2006). The Study of Language, Cambridge: Cambridge University Press.

Collins Co-build English Advanced Dictionary. (2001). Collins Co-build English Advanced Dictionary, HarperCollins Publishers. 